\title{
Effect of Ankle Taping and Exercise on EMG and Kinetics during Landing
}

\author{
Chung-Hwi Yi, PhD, PT ${ }^{1,2)}$, Denis Brunt, EdD, $\mathrm{PT}^{1)}$, \\ HyeOng-Dong Kim, PhD, $\mathrm{PT}^{1)}$, PAul Fiolkowski, PhD, ATC, $\mathrm{CSCS}^{1)}$ \\ 1) Department of Physical Therapy, University of Florida \\ ${ }^{2}$ Department of Physical Therapy, College of Health Science, Yonsei University: \\ 234 Maji-li, Hungob-myon, Wonju city, Kangwon-do 220-710, Republic of Korea. \\ TEL +82 33-760-2429 Fax +82 33-760-2496 E-mail: ych0406@dragon.yonsei.ac.kr
}

\begin{abstract}
The purpose of this study was to determine the effect of ankle taping and the combined effect of ankle taping and exercise on ankle stabilization under four different conditions (pre-taped, taped, walking on the treadmill, removal of tape) in drop landing from a $40 \mathrm{~cm}$ height. The subjects consisted of 14 healthy adult (four male, ten female) volunteers with ages ranging from 22-28 years. Preamplified EMG electrodes were attached to the soleus, tibialis anterior, vastus medialis, and biceps femoris. EMG and force plate data were collected at $500 \mathrm{~Hz}$. While standing on one leg, subjects hopped from a $40 \mathrm{~cm}$ height onto a force plate. The ankle of the right leg was then taped followed by a repeat of the hopping task, walking on a treadmill, and a second repetition of the hopping task. The hopping task was again repeated following the removal of the tape. Significant increases occurred in vertical ground reaction forces for the taped conditions compared with those in pretaped and untaped conditions. In the taped conditions, the soleus displayed a significant decrease in mean iEMG from impact to peak vertical ground reaction force $(\mathrm{p}<0.05)$. Results suggest that taping can provide enough mechanical support to limit ankle motion even after 30 minutes of walking on the treadmill. Additionally, diminished soleus iEMG activity may be related to an increase in the ground reaction forces upon landing from a jump.
\end{abstract}

Key words: Ankle taping, Drop landing, Kinetic analysis

(This article was submitted Mar. 31, 2003, and was accepted May 19, 2003)

\section{INTRODUCTION}

Athletic participation results in a relatively high risk of injury to the ankle joint. Ankle sprains are the most frequently reported injury in sport ${ }^{1)}$. The sport with the highest prevalence of ankle injuries is basketball, with over $50 \%$ of players having ankle joint problems that have resulted from ligament injuries $^{2)}$. Lateral ligaments of the ankle are also the most common site of injury in netball ${ }^{3,4)}$. A study has shown that $90-95 \%$ are inversion injuries causing partial or complete rupture of the anterior talofibular ligament and occasionally the calcaneofibular ligament ${ }^{5)}$.
Ankle taping is commonly used by athletic trainers or sports physical therapists to protect the ankle and to maximize its function during sporting activities $^{6,7)}$. Nevertheless, recommendations for or against the use of taping are not clear. Taping may provide prophylactic external stabilization during exercise but may also place the athlete at risk of injury due to restriction of joint movement ${ }^{8)}$. In addition, it appears that any positive effect of taping decreases with exercise ${ }^{9,10)}$.

Landing from a jump is a common occurrence in many sports where all lower extremity joints participate in energy absorption during landing ${ }^{11-16)}$. In addition, a forefoot landing will increase the role 
of the ankle musculature ${ }^{17}$.

When taping material stretches, or the limb sweats during exercise, taping is known to loosen ${ }^{18)}$. Exercise periods reported commonly ranged from 5 to 20 minutes but the amounts of activities with taping have differed between studies. Glick et al. ${ }^{18)}$ stated that tape would fail to support the ankle mechanically after 20 minutes of exercise. Bauer $^{19)}$ was less optimistic and concluded that athletic tape would fail to support the ankle effectively both during and after exercise.

The purpose of this study, therefore, was to determine the effect of ankle taping and the combined effect of ankle taping and exercise on ankle stabilization during landing from a jump. The results of this study will provide useful information for athletic trainers, and other professionals related to sports to judge the injury prevention effect of ankle taping.

\section{METHODS}

\section{Subjects}

Four male (mean age $=25.7$ years, $S D=2$ ) and 10 female (mean age $=23.8$ years, $\mathrm{SD}=2$ ) healthy adults volunteered for this study. All subjects signed informed consent forms approved by the University Institutional Review Board prior to their participation.

\section{Instrumentation}

Surface electrodes were applied to the center of the muscle bellies of the tibialis anterior, soleus, vastus medialis and biceps femoris muscles of the right leg. Conductive paste was first applied to the electrodes, which were held in place by adhesive tape. Each recording electrode consisted of two silver-silver chloride $1-\mathrm{cm}$ diameter electrodes embedded in an epoxy-mounted preamplifier system whose centers were spaced $2 \mathrm{~cm}$ apart. A reference electrode was attached to the medial aspect of the tibia on the left side. The EMG signals were band-pass filtered (20 $\mathrm{Hz}$ to $4 \mathrm{kHz}$ ) (Therapeutics Unlimited, Iowa City, Iowa) and full-wave rectified on-line. Final amplification was $2 \mathrm{k}$. One force plate, embedded in a level walkway $(10 \mathrm{~m}$ in length and $1.22 \mathrm{~m}$ in width), measured ground reaction forces. Processed EMG and amplified force platform signals were sampled on-line at a rate of $500 \mathrm{~Hz}$ for 5 seconds (BIOPAC Systems, Goleta, CA). All ground reaction forces were normalized to body weight.

\section{Procedures}

In order to exclude the influence of shoe type, all subjects wore low-top sneakers made by the same company when they performed the landing activity. Subjects stood on their dominant limb on a $40 \mathrm{~cm}$ high platform that was placed $20 \mathrm{~cm}$ from the edge of the force plate. Subjects were asked to hop down from the platform such that they landed safely without the need to readjust the landing leg. Subjects completed 3 practice trials followed by 3 experimental trials. The arms were not constrained during the landings and were generally held up and in front of the subjects for balance. The ankle of the right leg was then taped by a Certified Athletic Trainer using a standard prophylactic taping technique ${ }^{20}$. The taping configuration involved two circumferential anchor strips of tape applied at the forefoot region and proximally at the lower $1 / 3$ part of tibia. Three stirrups were applied in a basketweave configuration. Circulars were applied to fill in gaps, followed by two heel locks. The taping methods were applied with the ankle in neutral inversion-eversion and dorsiflexion. Materials utilized for the taping were one and one half inch tape (Johnson \& Johnson Products, Inc.), foam prewrap (Johnson \& Johnson Products, Inc.), and adherent spray (Tuf-skin, Cramer Products, Inc. Gardner, Kansas 55030). The subject repeated 3 hopping trials. The subject then walked for 30 minutes on a treadmill at comfortable self-selected speed. Following a 5 minute rest, the subject again repeated the 3 hopping trials. After removal of the tape, 3 additional hopping trials were performed.

\section{Data Analysis}

The EMG dependent variables were the integral of the muscle activity (iEMG) $100 \mathrm{~ms}$ prior to landing and from impact to peak vertical ground reaction force. Force platform measures included timing and amplitude of the vertical (Fz) ground reaction forces. The conditions were pre-taped trials, taped trials, tape and walk trials, and trials after tape removal. The EMG and force plate dependent variables are explained in Figure 1. Oneway analysis of variance (ANOVA) with repeated measures was used to analyze the data. In cases where there was a significant main effect $(p<0.05)$, a Bonferroni type adjustment was made to account for the possibility of Type I error occurring with multiple comparisons. 


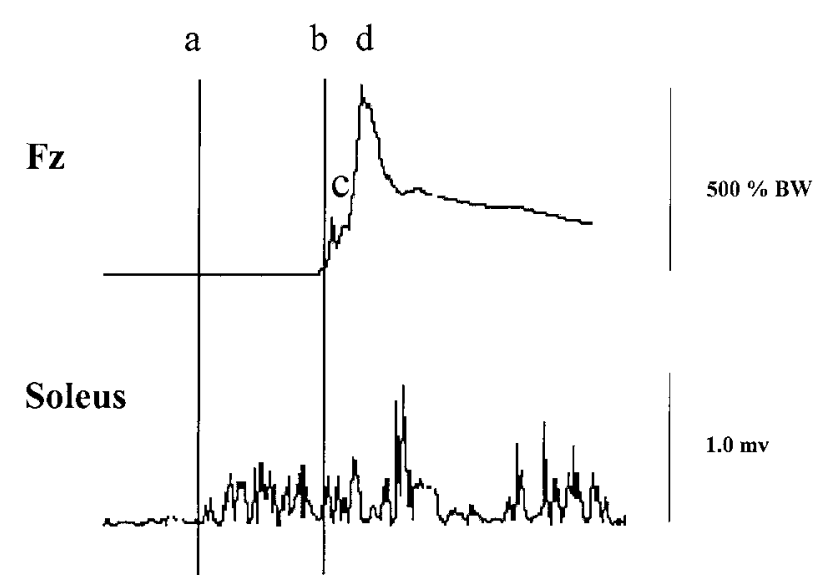

Fig. 1. Forceplate record and EMG of Soleus. Fz: vertical ground reaction force, a: $100 \mathrm{~ms}$ prior to landing, b: landing, c: peak Fz on toe impact, d: peak Fz on heel impact.

\section{RESULTS}

\section{Ground reaction forces}

Figure 1 shows a single trial from the taped trials condition. Mean data are shown in Table 1. Peak $\mathrm{Fz}$ at heel contact was significantly greater for the taped trials and the tape and walk trials compared to both the untaped conditions $\left(\mathrm{F}_{(3,39)}=10.79, \mathrm{p}<0.05\right)$. Mean peak $\mathrm{Fz}$ at heel contact for the taped trials was $550 \% \mathrm{BW}$ compared to $508 \% \mathrm{BW}$ for the untaped trials. The time to the peak force at toe contact and heel contact was significantly shorter for the taped conditions $\left(\mathrm{F}_{(3,39)}=8.65, \mathrm{p}<0.05\right)$ and $\mathrm{F}_{(3,39)}=13.28$, $\mathrm{p}<0.05)$. Mean times from landing to toe contact and heel contact for peak $\mathrm{Fz}$ for the taped conditions were respectively $10.24 \mathrm{~ms}$ and $36.98 \mathrm{~ms}$ compared to $11.82 \mathrm{~ms}$ and $41.15 \mathrm{~ms}$ for the untaped conditions.

\section{EMG activity}

EMG data are listed in Table 2 and Table 3. To identify the muscle preparation during landing, 100 $\mathrm{ms}$ iEMG data prior to impact were analyzed. There was no significant main effect for iEMG for any muscle in the $100 \mathrm{~ms}$ prior to landing (Table 2). The soleus muscle, however, showed the least activation taken from impact to vertical ground reaction under the taped and exercise with taping conditions $\left(\mathrm{F}_{(3,39)}=4.16, \mathrm{p}<0.05\right)$ (Table 3$)$.

\section{DISCUSSION}

Perhaps the most significant result of this study is the interaction of soleus EMG and Fz. Soleus appeared to behave differently. Biceps and vastus medialis increased with short time to peak Fz but not soleus. That is, with the tape conditions there was an increase in $\mathrm{Fz}$ but a decrease in soleus activity. The decrease in soleus EMG was due to the slightly decreased time to peak Fz. These data suggest that taping does in fact provide ankle support and in so doing restricts motion ${ }^{21)}$. The reduced ankle range of motion during landing would result in less energy being absorbed by the tissues controlling ankle motion, especially by the eccentric action of the posterior ankle musculature. $\mathrm{Fz}$ would increase and the time to peak $\mathrm{Fz}$ would therefore decrease. Hopper et al. ${ }^{3)}$ also reported a tendency to a shorter time to peak Fz when subjects were braced. They suggested that a decrease in energy absorption could increase the risk of ankle injury. Injury to the knee and hip joint is also

Table 1. Peak Fz (\% body weight) and time to peak Fz (ms)

\begin{tabular}{|c|c|c|c|c|c|c|c|c|c|}
\hline & \multicolumn{2}{|c|}{ Pre-taped 1) } & \multicolumn{2}{|c|}{ Taped 2) } & \multicolumn{2}{|c|}{ Exercise with Taping 3) } & \multicolumn{2}{|c|}{ Untaped 4) } & \multirow[t]{2}{*}{$\mathrm{P}$} \\
\hline & Mean & $(\mathrm{SD})$ & Mean & $(\mathrm{SD})$ & Mean & $(\mathrm{SD})$ & Mean & $(\mathrm{SD})$ & \\
\hline \multicolumn{10}{|c|}{ Peak Fz (\% Body Weight) } \\
\hline Toe Contact* & 151.86 & $(21.22)$ & 147.99 & $(23.48)$ & 155.37 & $(22.42)$ & 162.76 & $(28.09)$ & .033 \\
\hline Heel Contact** & 503.42 & $(34.23)$ & 549.51 & $(45.04)$ & 550.70 & $(47.83)$ & 512.41 & $(33.71)$ & .002 \\
\hline \multicolumn{10}{|c|}{ Time to Peak Fz (ms) } \\
\hline Toe Contact $\S$ & 11.71 & $(2.66)$ & 9.76 & $(2.04)$ & 10.71 & $(1.72)$ & 11.94 & $(2.73)$ & .002 \\
\hline Heel Contact & 41.57 & $(4.33)$ & 36.29 & $(2.96)$ & 37.67 & $(2.98)$ & 40.72 & $(4.27)$ & .000 \\
\hline
\end{tabular}

*: Bonferroni adjustment showed there were no significant differences across conditions. **: There were statistically significant differences in 1) vs 2), 1) vs 3), 2) vs 4), and 3) vs 4). §: Bonferroni adjustment in toe showed there were significant differences at the .05 in 1 ) vs 2 ), and 2) vs 3 ). $ף$ : Bonferroni adjustment in heel showed there were significant differences at the .05 in 1) vs 2), 1) vs 3), 2) vs 4), and 3) vs 4). 
Table 2. iEMG $(\mathrm{V} \cdot \mathrm{sec}) 100 \mathrm{~ms}$ pre-impact across muscles and conditions

\begin{tabular}{lccccr}
\hline Muscles & $\begin{array}{c}\text { Pre-taped } \\
\text { Mean (SD) }\end{array}$ & $\begin{array}{c}\text { Taped } \\
\text { Mean (SD) }\end{array}$ & $\begin{array}{c}\text { Exercise with Taping } \\
\text { Mean (SD) }\end{array}$ & $\begin{array}{c}\text { Untaped } \\
\text { Mean (SD) }\end{array}$ & P \\
\hline Soleus & $1.32 \times 10^{-2}$ & $1.23 \times 10^{-2}$ & $1.09 \times 10^{-2}$ & $1.12 \times 10^{-2}$ & 0.063 \\
Tibialis Anterior & $\left(0.45 \times 10^{-2}\right)$ & $\left(0.55 \times 10^{-2}\right)$ & $\left(0.41 \times 10^{-2}\right)$ & $\left(0.56 \times 10^{-2}\right)$ & \\
& $0.69 \times 10^{-2}$ & $0.69 \times 10^{-2}$ & $0.68 \times 10^{-2}$ & $0.71 \times 10^{-2}$ & 0.956 \\
Biceps Femoris & $\left(0.39 \times 10^{-2}\right)$ & $\left(0.51 \times 10^{-2}\right)$ & $\left(0.48 \times 10^{-2}\right)$ & $\left(0.54 \times 10^{-2}\right)$ & \\
& $0.75 \times 10^{-2}$ & $0.66 \times 10^{-2}$ & $0.60 \times 10^{-2}$ & $0.62 \times 10^{-2}$ & 0.253 \\
Vastus Medialis & $\left(0.48 \times 10^{-2}\right)$ & $\left(0.45 \times 10^{-2}\right)$ & $\left(0.31 \times 10^{-2}\right)$ & $\left(0.34 \times 10^{-2}\right)$ & \\
& $1.07 \times 10^{-2}$ & $1.07 \times 10^{-2}$ & $0.96 \times 10^{-2}$ & $0.92 \times 10^{-2}$ & 0.096 \\
& $\left(0.49 \times 10^{-2}\right)$ & $\left(0.41 \times 10^{-2}\right)$ & $\left(0.43 \times 10^{-2}\right)$ & $\left(0.38 \times 10^{-2}\right)$ & \\
\hline
\end{tabular}

Table 3. $\mathrm{iEMG}(\mathrm{V} \cdot \mathrm{sec})$ from impact to peak vertical ground reaction force (\%Body Weight)

\begin{tabular}{lccccr}
\hline Muscles & $\begin{array}{c}\text { Pre-taped } \\
\text { Mean (SD) }\end{array}$ & $\begin{array}{c}\text { Taped } \\
\text { Mean (SD) }\end{array}$ & $\begin{array}{c}\text { Exercise with Taping } \\
\text { Mean (SD) }\end{array}$ & $\begin{array}{c}\text { Untaped } \\
\text { Mean (SD) }\end{array}$ & P \\
\hline Soleus & $0.53 \times 10^{-2}$ & $0.37 \times 10^{-2}$ & $0.38 \times 10^{-2}$ & $0.48 \times 10^{-2}$ & 0.011 \\
& $\left(0.20 \times 10^{-2}\right)$ & $\left(0.18 \times 10^{-2}\right)$ & $\left(0.14 \times 10^{-2}\right)$ & $\left(0.19 \times 10^{-2}\right)$ & \\
Tibialis Anterior & $0.37 \times 10^{-2}$ & $0.35 \times 10^{-2}$ & $0.34 \times 10^{-2}$ & $0.35 \times 10^{-2}$ & 0.333 \\
& $\left(0.22 \times 10^{-2}\right)$ & $\left(0.24 \times 10^{-2}\right)$ & $\left(0.20 \times 10^{-2}\right)$ & $\left(0.22 \times 10^{-2}\right)$ & \\
Biceps Femoris & $0.39 \times 10^{-2}$ & $0.34 \times 10^{-2}$ & $0.35 \times 10^{-2}$ & $0.37 \times 10^{-2}$ & 0.064 \\
& $\left(0.29 \times 10^{-2}\right)$ & $\left(0.23 \times 10^{-2}\right)$ & $\left(0.32 \times 10^{-2}\right)$ & $\left(0.28 \times 10^{-2}\right)$ & \\
Vastus Medialis & $0.77 \times 10^{-2}$ & $0.71 \times 10^{-2}$ & $0.63 \times 10^{-2}$ & $0.71 \times 10^{-2}$ & 0.265 \\
& $\left(0.34 \times 10^{-2}\right)$ & $\left(0.36 \times 10^{-2}\right)$ & $\left(0.36 \times 10^{-2}\right)$ & $\left(0.48 \times 10^{-2}\right)$ & \\
\hline
\end{tabular}

Of the 4 muscles, only soleus muscle showed significant decrease across conditions.

possible as they play important roles in shock attenuation $^{22)}$. However, the results of this study are not sufficient to prove whether knee and hip joint kinetics are altered when ankle taping is used.

Considering the magnitude of the peak $\mathrm{Fz}$ in tape and walk trials, it is evident that the tape did not lose its restrictive ability to a significant extent even after 30 minutes of walking. We have to assume that the walking exercise was not strenuous enough to cause the tape to loosen.

Although the sample size is relatively small, the results of this study do provide preliminary data suggesting that ankle taping could potentially lead to injury. This opinion is based upon the increased vertical ground reaction force due to relatively decreased SOL EMG and, presumably, restricted range of dorsiflexion.

\section{CONCLUSION}

The result of this study indicates that the use of ankle taping can provide enough mechanical restriction to ankle motion after 30 minutes of walking on a treadmill, but could result in an increase in the risk of injury during landing.

\section{REFERENCES}

1) Bahr R, Bahr IA: Incidence of acute volleyball injuries: a prospective cohort study of injury mechanisms and risk factors. Scand J Med Sci Sport, 1997, 7: 166-171.

2) Brynnon BD, Renstrom PA: The effect of bracing and taping in sports. Ann Chir Gynaecol, 1991, 80: 230238.

3) Hopper D: A survey of netball injuries and conditions related to these injuries. Australian Journal of Physiotherapy, 1986, 32: 231-239.

4) Hopper D, Elliott BC, Lalor J: A descriptive epidemiology of netball injuries during competition: a 5 year study. Br J Sports Med, 1995, 29: 1-6.

5) Garrack JG, Requa RK: The epidemiology of foot and ankle injuries in sports. In: Yokum LA, ed. Clinics in Sports Medicine: Foot and Ankle Injuries. Philadelphia, WB Saunders, 1988, pp 29-36.

6) Cerney JV: Complete Book of Athletic Taping 
Techniques. West Nyack, New York: Parker Publishing Company, 1972.

7) Firer P: Effectiveness of taping for the prevention of ankle ligament sprains. Br J Sport Med, 1990, 24 (1): 47-50.

8) Hume PA, Gerrard DF: Effectiveness of external ankle support. Bracing and taping in rugby union. Sports Med, 1998, 25 (5): 285-312.

9) Heit EJ, Lephart SM, Rozzi SL: The effect of ankle bracing and taping on joint position sense in the stable ankle. J Sport Rehabil, 1996, 5: 206-213.

10) Shapiro MS, Kabo JM, Mitchell PW, et al.: Ankle sprain prophylaxis: an analysis of the stabilizing effects of braces and tape. Am J Sports Med, 1994, 22: 78-82.

11) Bobbert MF, MacKay M, Schinkelshoek D, et al.: Biomechanical analysis of drop and countermovement jumps. Eur J Appl Physiol, 1986, 54: 566-573.

12) Bobbert MF, Huijing PA, van Ingen Schenau GJ: Drop jumping: the influence of jumping technique on the biomechanics of jumping. Med Sci Sports Exerc, 1987, 19 (4): 332-338.

13) DeVita P, Skelly WA: Effect of landing stiffness on joint kinetics and energetic in the lower extremities. Med Sci Sports Exerc, 1992, 24: 108-115.

14) Dufek JS, Bates BT: Evaluation and prediction of impact forces during landings. Med Sci Sports Exerc, 1990, 22: 370-377.
15) Gross TS, Nelson RC: The shock attenuation role of the ankle during landing from vertical jump. Med Sci Sports Exerc, 1988, 20: 506-514.

16) Mizarahi J, Susak Z: Analysis of parameters affecting impact force attenuation during landing in human vertical free fall. Eng Med, 1982, 11: 141-147.

17) Kovacs I, Tihanyi J, Devita P, et al.: Foot placement modifies kinematics and kinetics during jumping. Med Sci Sports Exerc, 1999, 31 (5): 708-716.

18) Glick JM, Gordon RB, Nishimoto D: Prevention and treatment of ankle injuries. Am J Sports Med, 1976, 4 (4): 136-141.

19) Bauer T: The effectiveness of ankle taping and considerations for alternatives. In: Kreighbaum E, McNeil A: 6th International Symposium on Biomechanics in Sports. Bozeman (MT): International Society of Biomechanics in Sports, 1988, pp 407-418.

20) Arnheim DD: Modern Principles of Athletic Training. Brown and Benchmark, 1997.

21) Cordova ML, Ingersoll CD, LeBlanc MJ: Influence of ankle support on joint range of motion before and after exercise: a meta-analysis. J Orthop Sports Phys Ther, 2000, 30 (4): 170-177.

22) Fukuda H, Miyastita M, Fukuoda M: Unconscious control of impact force during landing. In: Biomechanics X-A. B. Jonsson B (ed.): Champaign, IL, Human Kinetics, 1987, pp 701-706. 